NBER WORKING PAPER SERIES

\title{
HAS PUBLIC HEALTH INSURANCE FOR OLDER CHILDREN REDUCED DISPARITIES IN ACCESS TO CARE AND HEALTH OUTCOMES?
}

\author{
Janet Currie \\ Sandra Decker \\ Wanchuan Lin \\ Working Paper 14173 \\ http://www.nber.org/papers/w14173 \\ NATIONAL BUREAU OF ECONOMIC RESEARCH \\ 1050 Massachusetts Avenue \\ Cambridge, MA 02138 \\ July 2008
}

We thank Lisa Bates and participants in the April 2007 Population Association of America meetings and two anonymous referes for helpful comments. We also thank Deborah Ingram, Susan Jack, Diane Makuc and Christopher Moriarity of NCHS for help with the NHIS data and income imputations. The findings and conclusions in this paper are those of the authors and do not necessarily represent the views of the Centers for Disease Control and Prevention. The views expressed herein are those of the author(s) and do not necessarily reflect the views of the National Bureau of Economic Research.

NBER working papers are circulated for discussion and comment purposes. They have not been peerreviewed or been subject to the review by the NBER Board of Directors that accompanies official NBER publications.

(C) 2008 by Janet Currie, Sandra Decker, and Wanchuan Lin. All rights reserved. Short sections of text, not to exceed two paragraphs, may be quoted without explicit permission provided that full credit, including $($ ) notice, is given to the source. 
Has Public Health Insurance for Older Children Reduced Disparities in Access to Care and Health Outcomes?

Janet Currie, Sandra Decker, and Wanchuan Lin

NBER Working Paper No. 14173

July 2008

JEL No. I11,I12

\section{ABSTRACT}

This paper investigates the effects of expanding public health insurance eligibility for older children. Using data from the National Health Interview Surveys from 1986 to 2005, we first show that although income continues to be an important predictor of children's health status, the importance of income for predicting health has fallen for children 9 to 17 in recent years. We then investigate the extent to which the dramatic expansions in public health insurance coverage for these children in the past decade are responsible for the decline in the importance of income. We find that while eligibility for public health insurance unambiguously improves current utilization of preventive care, it has little effect on current health status. However, we find some evidence that Medicaid eligibility in early childhood has positive effects on future health. This may indicate that adequate medical care early on puts children on a better health trajectory, resulting in better health as they grow.

Janet Currie

International Affairs Building

Department of Economics

Columbia University - Mail code 3308

$420 \mathrm{~W} 118$ th Street

New York, NY 10027

and NBER

jc2663@columbia.edu

Sandra Decker

Senior Service Fellow

National Center for Health Statistics

Centers for Disease Control and Prevention

3311 Toledo Road (Room 3316)

Hyattsville, MD 20782

and NBER

sdecker@cdc.gov
Wanchuan Lin

Guanghua School of Management

Peking University

Beijing 100871, P.R.China

wanchuan@gmail.com 


\section{Introduction}

Children of wealthier parents are healthier than other children. This relationship is apparent in key indicators of child health, such as activity limitations, asthma, and mental health problems (Currie and Lin, 2007; Newacheck, 1994) . Poor health in childhood is likely to affect adult well-being both directly, through its effects on health, and indirectly, through inhibiting the child's accumulation of human capital. Since 17 percent of all U.S. children under age 18 live in families with income below the Federal poverty level, it is essential to have a better understanding of the mechanisms underlying the relationship between income and health (U.S. Bureau of the Census, 2004).

Expanding health insurance for low income children continues to be a main goal of U.S. health policy for children. The primary policy tool aimed at meeting this goal has been liberalization of the eligibility criteria for public health insurance. Previous research has shown that expansions in eligibility of infants and young children for public health insurance have been effective in improving their health and access to care (Currie and Gruber, 1996b; Dafny and Gruber, 2005; Mathematica Policy Research Inc., et al., 2005).

This paper investigates the effects of expanding public health insurance eligibility on the health of older U.S. children. Older children are an especially interesting group because income becomes an increasingly important determinant of health as children grow older . We show, using data from the National Health Interview Surveys for 1986 to 2005, that the importance of income for predicting health has fallen for children 9 to 17 in recent years.

What explains this decline in the importance of income? It is natural to think of the dramatic expansions in public health insurance coverage for these children which 
have occurred over the past decade. If access to health insurance mitigates the health effects of low income, then one might expect to find that the relationship between income and health has weakened among the targeted older children. This improvement in health could stem either from the contemporaneous effects of gaining health insurance coverage, or from the lagged effects of having been covered at younger ages. Thus, in our analysis, we look at both present and lagged effects of public health insurance expansions.

The paper proceeds as follows. First, we present some background about the Medicaid expansions, describe the data, and document the reduction in the importance of income for the health of older children after 1996. Then, we explore the extent to which expansions of public health insurance eligibility to these children have been responsible for improvements in their health and access to care.

We find that while eligibility for public health insurance unambiguously improves current utilization of preventive care, it has little effect on current health status. However, we find some evidence that Medicaid eligibility in early childhood has positive future effects on health. This may indicate that adequate medical care early on puts children on a better health trajectory, resulting in better health at older ages.

\section{Background}

As of the early 1980s, public health insurance under the Medicaid program was available primarily to children of welfare mothers, which meant that the income cutoffs for program eligibility were below the poverty line in many states. Beginning in 1984, Congress expanded Medicaid coverage to pregnant women, infants and younger children not on welfare. By April 1990, states were required to offer coverage to children below age six in families with income up to 133 percent of 
the federal poverty line. This meant that young children had access to public health insurance while older children in similarly situated families did not.

However, since the passage of the Omnibus Budget Reconciliation Act (OBRA) of 1990, the focus of the Medicaid expansions has shifted to older children. OBRA 1990 required states to increase the eligibility of older children by covering one additional year of age per year. Starting in July 1991, states were required to provide coverage to all children under age 19, who were born after September 1983 and lived in households with incomes less than $100 \%$ of the Federal Poverty Line. Hence, all poor children under age 18 were covered by 2001.

The State Child Health Insurance Program (SCHIP) initiated in 1996 provided an additional source of public health insurance coverage for low income children. Under SCHIP, states have had the option of extending Medicaid, creating a new SCHIP insurance program, or offering a combination. Medicaid and SCHIP work somewhat differently. Medicaid is an entitlement, which means that all eligible children are covered, while SCHIP is a block grant. Under SCHIP, if the states run out of money, then they put people on a waiting list.

Still, the evidence suggests that Medicaid and SCHIP have had similar impacts on the lack of insurance among children (LoSasso and Buchmueller, 2004). In analyses which are not shown below, we tried to distinguish between the effects of Medicaid and SCHIP programs, but did not see differential impacts on the outcomes we examine. Consequently, in this paper we do not distinguish between these two programs.

Table 1 shows the weighted average of the income eligibility cutoffs for public health insurance across states as a percentage of the federal poverty line for each year 
and child age group ${ }^{1}$. We initially examined four age groups: 0-3, 4-8, 9-12, and 14-17 in order to divide children into roughly equally sized groups. The Medicaid income eligibility cutoff differs by state, year, child age, and in some cases it also depends on a child's birth month and year. For simplicity, the table only shows the average cutoffs aggregated by child age group over years, weighted by the population in each cell. As is apparent from Table 1, Medicaid expansions for younger children started before expansions for older children. The first year in which the average cutoff for 0 to 3 year old children reached 100\% of the federal poverty line was 1989 . In 1990, the average cutoff for 4 to 8 year old children reached $100 \%$, while the average cutoffs for children 9 to 12 and 13 to 17 reached 100\% in 1994 and 1997, respectively. If contemporaneous health insurance is a major determinant of children's health status, then one might expect to see health improve in the same staggered way across these age groups.

Even though the Medicaid expansions started later for older children, the expansion for older children in the past 10 years has been dramatic. In 1996, the average child aged 0 to 3 was covered if his or her household income was under 155\% of the Federal Poverty Line (FPL), but the average 12 to 17 year old child was only covered if he or she lived in a household with income under 94\% of the FPL. However, due to the rapid expansions for older children in the past 10 years, by 2005 the eligibility cutoffs had converged to $220 \%$ of the FPL for all children.

As a source of identification, we rely on the fact that the expansions in Medicaid/SCHIP eligibility for older children relative to younger children have happened at different times and with different magnitudes in different states. Although there is significant variation across child age groups over time, Table 1

\footnotetext{
1 Data on eligibility are collected from several sources including National Governors Association (2003), Cohen-Ross and Cox (2005), and Rosenbach et al. (2001).
} 
masks the fact that there is also a great deal variation from state to state. To illustrate this point, it is instructive to compare eligibility cutoffs in for several states, as shown in Figure 1. Figure 1 shows the eligibility cutoffs by child age group over time for California, Illinois, New York, and Texas. These states were chosen for illustrative purposes since they are all large and important states and they show quite different time patterns.

California is a relatively generous state and covered all poor children over the entire period we examine. Gaps between older and younger children in terms of income eligibility cutoffs were relatively small, and the cutoff converged to $250 \%$ of poverty by 2000 for all children. Illinois was less generous, and had larger age gaps in eligibility cutoffs over much of the period. The oldest children were covered only if their incomes were below about $60 \%$ of the FPL until 1997, when cutoffs for all groups rapidly began to converge to just below 200\% of the FPL. New York shows a bumpier pattern, with cutoffs first rising and then declining for the youngest age groups, and with cutoffs for all ages converging to 250\% of the FPL by 2001 . Finally, Texas shows the largest gaps between the cutoffs for older children (less than $50 \%$ of the FPL) and the cutoffs for younger children (150\% of the FPL) over much of the period. But as in other states, in 2001, cutoffs converge to about $200 \%$ of the FPL.

Figure 2 shows the huge overall increase in public health insurance for children that has taken place since the mid-1980s. The figure shows that the expansion of Medicaid alone and of Medicaid plus SCHIP moved roughly in parallel after 1996, and that over the entire period, the fraction of children eligible for public health insurance expanded from less than $10 \%$ to over $25 \%$. 


\section{Data}

In our analysis, we use data from the 1986 to 2005 National Health Interview Survey (NHIS) ${ }^{2}$. The NHIS is an annual cross-sectional survey that provides information on health status and demographic attributes of a large sample of American adults and children. The NHIS follows a multistage probability design using geographically defined sampling units to select a nationally representative sample of households for interview. Our analysis spanned two sample design periods of the NHIS: 1986-1994, and 1995-2005. Our analyses used the NHIS public use file variance estimation variables that are available for pooled NHIS data for 1986-1994, 1995-1996, and 1997-2005.

We are interested in the potential impact of expansions of eligibility for public health insurance on the relationship between family income and health status and on the use of health services among children. Our dependent variable for health status follows the previous literature on child income-health gradients, and considers the parent's report of whether the overall health status of the child is excellent, very good, good, fair, or poor. We also use this variable to examine whether a child is in less than excellent health (a little less than half of children fall into this category).

To investigate the effect of public health insurance expansions on the utilization of healthcare for children, we ask whether or not a child had any doctor visits in the previous year. A potential problem with interpreting utilization measures is that they confound access and morbidity. One way to surmount this problem is to focus on utilization that is explicitly preventive, and therefore unaffected by morbidity. Pediatric best-practice recommends at least one doctor's visit per year for children; therefore, we interpret the absence of a doctor's visit in the previous year as a true access problem whatever the underlying morbidity.

\footnotetext{
${ }^{2}$ For more information about NHIS, please visit: http://www.cdc.gov/nchs/nhis.htm.
} 
Since we are interested in the potential impact of Medicaid/SCHIP eligibility on the relationship between family income and child health and the use of health services, family income is a key independent variable in our analysis. A potential concern that emerges from using the NHIS data is that income information is missing for an average of $14.7 \%$ of our sample. We impute income for those who are missing data. For 1990 to 2005, we use the income imputation files created by NCHS. For data prior to 1990, we impute income using methods similar to those used by NCHS. A second issue is that the NHIS reports household income in ranges. We assign incomes to households within reported or imputed income ranges by using the 1986 to 2005 March Current Population Survey (CPS) data.

An online appendix describes how we impute income for 1986-1989 and how we assign an exact income to income ranges for 1986-2005. It also shows estimates obtained using a consistent income imputation method over the full sample, and that they do not differ from those reported below. Finally, the appendix discusses some issues having to do with the redesign of the NHIS survey in 1997.

In addition to examining children's health and use of health services as a function of the (log of) income (in 1986 dollars), we control for other known determinants of children's health and health care utilization including (the log of) family size, child gender, and indicators for race and ethnicity (whether the child was non-Hispanic white, black or other race, or Hispanic); dummies for each year of child age; dummies for each survey year; whether the mother (father) was present in the household; whether the mother (father) had less than 12, 12, or more than 12 years of education interacted with whether the mother (father) was present in the household; mother (father) age interacted with whether the mother (father) was present in the household; and whether the mother (father) was unemployed interacted with whether the mother (father) was present in the household. 
Because we use a restricted version of the NHIS data that includes state identifiers, we are able to both match information about state Medicaid rules to the children in the sample, and to control for state fixed effects in the analysis. The inclusion of the state fixed effects to capture time-invariant characteristics of the state is potentially important when we attempt to estimate the casual effects of Medicaid expansions.

In drawing our final sample for analysis, we first consider all children under the age of 18 resulting in 548,789 children in the NHIS 1986-2005. We drop approximately 1 percent of the sample (6,613 records) for which income imputations were not provided or income could not be computed due to missing information on variables used to impute income. For the sake of comparability with previous work, we then follow Case, Lubotsky, and Paxson (2002) in finalizing our sample for analysis. We drop children who were not living with at least one of their parents, who were not children of a reference person or spouse, or were living in a household containing more than one family. These sample restrictions result in dropping about 9 percent $(48,621)$ of the original sample of 542,176 children with nonmissing information on family income. We do this both for comparability with previous work and because there may be some doubt about whether reported family income accurately reflects the income over which the child may have a claim in the less standard households. Dropping these children also allows us to consider parental age, education and employment status as independent variables in predicting child health. Identification of parents is not possible for all children of non-reference person parents in the NHIS prior to 1998. Among the remaining 493,555 children, we again follow Case, Lubtsky, and Paxson (2002) and drop about 1.7 percent of children in households where children in the household are reported to be of different race since we believe that race may sometimes be mismeasured in these cases or that 
the children are being fostered. Of the remaining children, we drop about 2.7 percent due to missing information on variables such as race, parental attributes, family size, and self-reported health, or because of a birth month and year that did not match the reported age of the child in years. Our final sample size for health status is 474,164 children under the age of 18 from the NHIS 1986-2005. (Our final sample size for doctor visits is 376,889 . The sample size for doctor visits is smaller because, beginning in 1997, the question on doctor visits is asked only of a subset of children in the NHIS - sample children.)

Because the children in our sample may not be a random sample of the NHIS children, we have performed all of the analyses in this paper including the 48,621 children dropped due to reasons related to family structure. As shown in the appendix, none of the analyses in this paper were materially affected.

Summary statistics for key variables by child age group (using the age categories of 0-3, 4-8, 9-13 and 14-17) and by period are provided in Table 2. The top panel refers to the period 1986 to 1995 (Period 1), and the bottom panel covers the period 1996 to 2005 (Period 2). The first six rows in each panel of Table 2 show the means of the dependent variables. For example, the first row of each panel reports the mean for self reported health (with values 1= Excellent, 2= Very good, 3= Good, 4= Fair and 5=Poor). The second row reports the mean for self reported health, but only for children who live under $100 \%$ of the Federal Poverty Line.

As we can see from both panels, children's health deteriorates with child age, especially for children in poor families. In both periods, more than half of parents reported their children to be in excellent health, with more parents reporting children to be in excellent health in Period 2. Moreover, the improvement in health in Period 2 is more substantial for poor older children than for wealthier older children.

Table 2 also shows that the percentage of children who went without any doctor 
visits in the past 12 months fell over time, indicating that children have better access to medical care in Period 2. One thing to notice is that older children are more likely to have lacked a doctor visit in the past 12 months than younger children, especially poor older children.

Subsequent rows of Table 2 show the means of the independent variables used in our regression analysis. For instance, the mean family income is \$29,726 (1986 \$) in Period 1, and it increases to $\$ 38,215$ in Period 2. It is not surprising to see that older children live in families that are richer than those of younger children. Around 20 percent of the children live without their fathers and around 2 percent are living apart from their mothers. The sample (in Period 1) is 70 percent non-Hispanic white, 14 percent non-Hispanic black, 12 percent Hispanic, and 4 percent non-Hispanic other race.

\section{Empirical Strategy}

We began our analysis with a graphical exploration of the relationship between income and health in four sub-periods, 1986 to 1990, 1991 to 1995, 1996 to 2000, and 2000 to 2005 . We estimated the conditional expectation of health status in the NHIS as a function of the log of family income by time period using a locally weighted regression smoother, which allows the data to determine the shape of the function, rather than imposing, for example, a linear or quadratic form.

Figure 3 shows the resulting estimates for the earliest and latest sub-periods. It is clear that at the low end of the income distribution, the lines for all four age groups shift down considerably over time. For the youngest and poorest children, the mean shifts from approximately 2 to about 1.8 . For the oldest poor children it shifts from 2.2 to 2.1 , where lower numbers indicate better health. At the $25^{\text {th }}$ percentile of income, the improvements are smaller for all age groups, while at the median income, 
it appears that overall health status improved slightly among the youngest children, but worsened slightly among older children leading the lines to "fan out" slightly. This suggests that there may be unobserved factors causing a slight deterioration of the health of older children over the period. To the extent that these factors affect all older children, any positive effects due to the Medicaid/SCHIP expansions to older children will tend to be under-estimated in this type of simple comparison.

These graphs give a good sense of underlying trends in the data, but do not control for other covariates, or for factors that could affect the health of all children of a given age. Hence we turn to estimating models of the effects of income on health status and utilization, of the form:

$$
\text { (1) } y=b_{0}+b_{1} I N C+b_{2} I N C * T I M E+b_{3} X+b_{4} \text { STATE }+b_{5} \text { YEAR }+e
$$

where $y$ is a measure of health status or the utilization of health services of each child, INC is household income, TIME is a vector of three time dummy variables representing the periods 1991 to 1995, 1996 to 2000, and 2000 to 2005, X is the set of control variables shown in Table 2 and discussed above, STATE is a vector of state dummy variables, and YEAR is a vector of year dummies.

We estimate these models separately for each of the four age groups, using either ordered probits or linear probability models. All analyses in the paper use sample weights (with person weights replaced by sample child weights for "no doctor visit in the past year” beginning in 1997). In addition, all analyses account for the possibility of non-independence of observations within NHIS sampling units in the same design period to the extent possible, by using a Taylor series linearization method for variance estimation (Williams, 2000). ${ }^{3}$ The coefficients $b_{2}$ allow us to test the hypothesis that

\footnotetext{
${ }^{3}$ Since the NHIS public use file variance estimation variables are different for 1995-1996 than for 1997-2005, the analysis strategy treats these two periods as distinct design periods for the purposes of variance estimation.
} 
the relationship between income and outcomes changes over time within age categories.

In order to test whether increases in Medicaid/SCHIP eligibility have affected the relationship between income and children's health, we pool age groups to take advantage not only of variation in Medicaid/SCHIP eligibility within states over time, but also variation within state-age groups over time. Hence we pool all child age groups together and estimate models of the form:

(2) $y=b_{0}+b_{1}$ PUBINS $+b_{2} I N C+b_{3} I N C * A G E 9-17+b_{4} I N C * T \_1996-2005+$ $b_{5}$ AGE9-17*T_1996-2005 $+b_{6} I N C * A G E 9-17 * T \_1996-2005+b_{7} X+b_{8} S T A T E+$ $b_{9} Y E A R+b_{10}$ STATE*AGE9-17 + $e$, where PUBINS indicates that the child is eligible for public health insurance, AGE9-17 indicates that they are aged 9 to 17 and $T \_1996-2005$ indicates that it is the second half of our time period. We focus on the age group 9 to 17 in these regressions because, as we will show below, the reduced effect of income on child health over time is apparent for the 9 to 12 and 13 to 17 year olds.

In this model, the two-way interactions control for any differential effect of income on the health of older children throughout the period and for differential effects of income in the later period for all children. We control for both state effects and state effects interacted with child age group in order to separate any effect of Medicaid eligibility on child health from other influences on child health that may vary by state or state and age.

We focus on the coefficient $b_{6}$ which measures the extent to which income had a differential effect for older children in the later period. Our hypothesis is that Medicaid/SCHIP eligibility may explain this differential effect. Therefore, we estimate (2) with and without PUBINS and ask whether the estimate of $b_{6}$ becomes smaller in absolute value or loses statistical significance when PUBINS is included in 
the model. Whether or not the child is eligible for public insurance is computed by comparing the child's family income to the appropriate Medicaid/SCHIP income eligibility cutoffs by state, year and child age.

Two problems, however, may prevent us from seeing the causal effect of the expansions. First, even though we control for observable variables that directly affect eligibility for Medicaid, such as income, the absence of a male head, and the number of children in a family, persons who are eligible for public health insurance may have other unobserved characteristics that affect their health. Second, a sick child may cause lower parental income, leading to a spurious correlation between public health insurance eligibility and poor health.

For these reasons, following Currie and Gruber (1996a; 1996b), we instrument for individual Medicaid/SCHIP eligibility using an index of the generosity of the state's public health insurance programs. This index is the fraction of a fixed group of children drawn from the same age group and year who would be eligible for public health insurance in each state. This instrument was constructed by sampling 500 children by single year of age and calendar year from the CPS data, and then calculating the fraction of this fixed group of children who would be eligible for Medicaid/SCHIP in each state and year. This approach allows us to construct a measure of public health insurance generosity for each state, year and age group that abstracts from individual or family-level determinants of eligibility and outcomes.

As Currie and Gruber discuss, use of this instrument assumes that the state-to-state variations in the timing of expansions of public health insurance generosity were independent of other factors that would influence child health and utilization of care. Since much of the expansion was in response to federal government mandates, as well as the creation of the federal SCHIP program, we think this is a reasonable assumption. 
Figure 4 summarizes the results of our calculation of the simulated instrument. It shows the fraction of children eligible for public health insurance in each age group and year. As in Figure 2, we see the divergence between older and younger children which opens up in the early 1990s, and starts to close again in the late 1990s. Unlike the eligibility cutoffs, the fractions eligible do not completely converge. This is partially due to the fact that older children tend to live in wealthier households.

Finally, we are interested in seeing whether past eligibility for Medicaid affects current health status. Since the NHIS is not a panel and does not record state of birth, it is not possible to control for whether the child was actually eligible for Medicaid/SCHIP at birth, or to know what state they were born in. Hence, the best that we can do is to assume that most children remain in the state in which they were born and examine the effect of Medicaid/SCHIP generosity. Therefore, we estimate reduced form models where health status and whether the child had a no doctor visit in the past year are regressed on the fraction of children who were eligible in the child's birth cohort and current state of residence at various ages. ${ }^{4}$ Because we are interested in the effect of lagged health insurance eligibility on the health status of older children, we estimate these models using only the children aged 9-17. These models are of the form:

(3) $y=b_{0}+b_{1}$ PUBINS $+b_{2} I N C+b_{3} I N C * T \_1996-2005+b_{4} X+b_{5} S T A T E+$ $b_{6} Y E A R+e$, where PUBINS is now a measure of the fraction eligible for public health insurance when the child was age 0 , age 1 , age 2, etc. Eligibility at each age is included in a

\footnotetext{
${ }^{4}$ Medicaid eligibility cutoffs prior to 1986 are calculated using AFDC rules and expressed relative to the poverty level as in Aizer and Grogger (2003). AFDC payment standards for a family of four were obtained back to 1969 (the year of birth for 17 years olds in NHIS 1986) from Committee on Ways and Means (various years) and, for the early years, from the Office of Family Assistance (various years). $\quad$ AFDC payment standards were obtained for all years beginning with 1969 except for 1977. The 1977 payment standards were assumed to be equal to the mean of the 1976 and 1978 standards by state. The fraction of children eligible for Medicaid by state, year and year was then calculated back to 1969 using data from the CPS.
} 
separate regression since there is a good deal of multicollinearity between eligibility at various ages.

\section{Results}

Table 3 presents estimates of equation (1) from an ordered probit model. The dependent variable consists of the parent's overall assessment of the child's health status, which takes the values 1 to 5 . The negative coefficients on log family income indicate that the higher the family income, the better the child's health. The interactions between income and the later time periods are statistically significant for the older children. For children aged 9 to 12 the importance of income is reduced in the 2000 to 2005 period, while for children aged 13 to 17 it falls both in the 1996 to 2000 period and (by somewhat more) in the 2000 to 2005 period. For children 13 to 17, the coefficient falls from -.22 to -.17, a decline in absolute value of almost $25 \%$.

Still, the pattern of coefficients in Table 3 casts some doubt on the hypothesis that this decline in the importance of income is due primarily to public health insurance expansions. Given that these expansions affected the youngest children first, one might have expected to see effects on children 4 to 8 in the 1991 to 1995 period, effects on 9 to 12 year olds in the 1996 to 2000 period, and so on.

Table 4 shows the equivalent estimates from a linear probability model in which the dependent variable is whether the child is in less than excellent health. The findings are qualitatively similar, though somewhat less precisely estimated. Now, the only statistically significant interactions are in the equation for children aged 13 to 17 and in the equation for children 4 to 8 (for 1996 to 2000). Still, the estimated effects are sizable, reducing the effect of income from -.075 in the base period to -.058 in 2000 to 2005 among the oldest children.

Table 5 shows estimates of equation (1) using whether the child went without a 
doctor visit in the past year as the dependent variable. Once again, the effect of income is negative - children with higher income are less likely to have lacked any doctor visits during the preceding year. The interaction terms are all significantly positive for the younger age groups, suggesting that income became a less important determinant of having any doctor visits over time. Among children 4 to 8 , the estimated effect changes from -.037 in 1986 to 1990 to -.014 in 2000 to 2005, more than a 50\% reduction! By 2000-2005, 9 to 12 year old children have also experienced a decrease in the probability of having of going without a doctor visit in the past year.

This pattern of effects is roughly what we would expect if the improvements in doctor visits were due to expansions in eligibility for public health insurance. We see improvements first in younger children, followed by improvements among progressively older children. We do not see any significant effects in the oldest group however, suggesting that it may take some years for the effects of the expansions on access to be felt.

Table 6 shows estimates of equation (2). The first three columns show estimates from models using the probability that the child is in less than excellent health as the dependent variable. We obtain estimates that are qualitatively similar to those in the previous tables. The effect of income is negative, indicating that higher income children are in better health. The effect of income is greater for older children, but this differential declines in the later time period - in other words, the interaction among family income, older child age, and later time period is significant and positive. The estimates in column (1) suggest that for older children the effect of log income declines from -.070 to -.061 between the two periods.

Column (2) shows estimates that add a measure of whether the child is Medicaid/SCHIP eligible to equation (2). Ordinary Least Squares (OLS) estimates 
suggest that eligibility for public health insurance worsens health. This finding is likely a result of a correlation between public insurance eligibility and omitted factors indicating poor health, an explanation that is supported by the instrumental variables estimate shown in column (3). When we use the fraction eligible for public health insurance in the child's state, age, and year as an instrument, eligibility for Medicaid or SCHIP is estimated to have a small and statistically insignificant effect of the anticipated sign. Moreover, adding eligibility causes virtually no change in $b_{6}$, the coefficient on the triple interaction term. Hence, the results suggest that income has become a less important determinant of the health of older children over time, but that this does not appear to be due to increases in their contemporaneous public health insurance eligibility.

Columns (4) to (6) of Table 6 show estimates from model (2) where the dependent variable is the probability that the child had no doctor visit in the previous year. Here, $b_{6}$ is not statistically significant, but individual eligibility for Medicaid/SCHIP has a strong and significant effect, even in the OLS models. This is consistent with Currie and Gruber (1996b). Column (6) shows that instrumenting individual eligibility with the group fraction eligible results in an even larger estimate—children with Medicaid/SCHIP eligibility are 6.8 percentage points less likely to have gone without a doctor's visit in the previous year.

Since health is a stock, it is affected by past investments as well as current ones. Hence, it may not be surprising if contemporaneous Medicaid/SCHIP eligibility has little effect on overall health status. Hence, as discussed above, we estimate models in the form of Equation (3) for the subsample of children aged 9 to 17. The results are shown in Table 7.

The first panel shows estimates from models with "less than excellent health" as the dependent variable. The estimates suggest that more generous health insurance 
coverage at ages 2, 3, and 4 is associated with better health status when the child is 9 to 17. The point estimates for effect of health become monotonically larger from birth to age 3, and then grow smaller again. The relatively small estimate for age 0 might reflect measurement error if families are most likely to change states when their children are infants. The point estimate for age 3 implies that a one hundred percentage point increase in the fraction eligible (from no children to eligible to all children eligible), would reduce the probability that an average older child is in poor health by about 5 percentage points. This is a nearly 11 percent improvement relative to the average--about 46 percent of children aged 9 to 17 are in less than excellent health. Given the crudeness of our health measure, this is likely to be a lower bound on the true effect of past health insurance on child health.

The second panel shows models with "no doctor visit in the past year" as the dependent variable. This panel suggests that the largest effects on going without doctor visits are associated with increases in the generosity of public insurance eligibility when the child was aged 1 or 2 , and again, the coefficients decline thereafter. At age 8, the coefficient is -.059.

It is important to emphasize that we are not looking at the number of doctor visits, but at whether children had any doctor visits at all in the past year. Policy statements by the American Academy of Pediatrics consistently recommend at least one physician visit per year for all children aged 21 and under (American Academy of Pediatrics, 1995; American Academy of Pediatrics, 2000; American Academy of Pediatrics, 2007).

Hence, reductions in the number of children going without doctor visits suggest that contemporaneous health insurance coverage increases access to care. Our results also suggest that lagged coverage has important effects (perhaps by making it more likely that the family has gotten in the habit of taking the child for regular 
checkups, and has a usual source of care.) It is quite possible that lagged coverage encourages use of medical care for minor illnesses, though we expect that such an effect would be reflected in the number of doctor visits, rather than by our measure of whether the child had any doctor visits at all.

The estimated effect of past Medicaid/SCHIP eligibility on future access to care is sizeable. The point estimate for age 1 or 2 implies that making all children eligible would reduce the probability that an average older child had no doctor visit by nearly 9 percentage points. This is a nearly 41 percent improvement relative to the average fraction of 9-17 year old children who have had no doctor visit in the past year of about 22 percent.

\section{Conclusions}

Income continues to be an important predictor of child health status in the United States. However, the importance of income to the health of older children has diminished in recent years. Large expansions of public health insurance coverage to cover older children are a possible explanation. However, we find that while increases in contemporaneous Medicaid/SCHIP eligibility have strong effects on access to care, they do not increase the probability that an older child is in good health.

We suggest that this may be because health is a stock which reflects the results of cumulative investments, and offer suggestive evidence that children in states that had more generous policies in place when they were very young are healthier as 9 to 17 year olds. This may indicate that adequate medical care in early childhood puts children on a better health trajectory, resulting in better health at older ages. If this hypothesis is found to be correct, then it is consistent with a growing literature suggesting that conditions in early childhood, and even prenatally, matter for 
children’s longer-term outcomes (Barker, 1998; Heckman, 2007), and with the emerging literature in neuroscience and pediatrics that posits that "sensitive periods" for functions such as brain development occur prior to adolescence (Andersen, 2003;

Ito, 2004). 


\section{References}

Aizer A, Jeffrey G. Parental Medicaid expansions and health insurance coverage. Cambridge, Ma: National Bureau of Economic Research (NBER) Working Paper No. 9907; 2003.

American Academy of Pediatrics. Committee on Practice and Ambulatory

Medicine. Recommendations for preventive pediatric health care. Pediatrics 1995; 96; 373-374.

American Academy of Pediatrics. Recommendations for preventive pediatric health care. Pediatrics 2000; 105(3); 645-646.

American Academy of Peditrics. Recommendations for preventive pediataric health care. Pediatrics 2007; 120; 1376.

Andersen, SL. Trajectories of brain development: point of vulnerability or window of opportunity? Neuroscience and Biobehavioral Reviews 2003; 27: 3-18.

Barker DJP. Mothers, babies and health in later life. Churchill: Livingston: Edinburgh, U.K.; 1998.

Case A, Lubotsky D, Paxson C. Economic status and health in childhood: The origins of the gradient. American Economic Review 2002; 92(5); 1308-34.

Cohen-Ross D, Cox L. In a time of growing need: State choices influence health coverage access for children and families: A 50-state update on eligibility rules, enrollment, and renewal procedures, and cost-sharing practices in Medicaid and SCHIP for children and families. Kaiser Commission on Medicaid and the Uninsured: Washingon DC; 2005.

Currie J, Gruber J.. Health insurance eligibility, utilization of medical care, and child health. Quarterly Journal of Economics 1996a; 111(2); 431-66.

Currie J, Gruber J. Saving babies: The efficacy and cost of recent changes in the Medicaid eligibility of pregnant women. The Journal of Political Economy 1996b; 104(6); 1263-96. 
Currie J, Lin W. Chipping away at health: More on the relationship between income and child health. Health Affairs 2007; 26(2); 331-44.

Dafny L, Gruber J. Public insurance and child hospitalizations: Access and efficiency effects. Journal of Public Economics 2005; 89(1);109-29.

Heckman JJ. The technology and neuroscience of capacity formation. Proceedings of the National Academy of Sciences (PNAS) 2007; 104(33);13250-55.

Ito, M. "Nurturing the brain" as an emerging research field involving child neurology. Brain \& Development 2004; 26; 429-433.

Lo Sasso AT, Buchmueller TC. The effect of the State Children's Health Insurance Program on health insurance coverage. Journal of Health Economics 2004; 23(5); 1059-82.

Mathematica Policy Research Inc., Kenney G. , Dubay L, Hill I, Sommers A, Zuckerman S. Congressionally mandated evaluation of the State Children's Health Insurance Program: Final report to Congress. Mathematica Policy Research Inc.: Washington DC; 2005

National Governors' Association. State Medicaid coverage of pregnant women and children. National Governors' Association: Washington DC; 2003.

Newacheck P. Poverty and childhood chronic illness. Archives of Pediatrics and Adolescent Medicine 1994; 148(11); 1143-49.

Office of Family Assistance, Administration for Children and Families. Characteristics of state plans for Aid to Families with Dependent Children. U.S. Department of Health, Education and Welfare (HEW): Washington, DC; Various years.

Raghunathan TE, Lepkowski JM, Van Hoewyk J, Solenberger P. A multivariate technique for multiply imputing missing values using a sequence of regression models. Survey Methodology 2001; 27(1); 85-95.

Rosenbach M, Ellwood J, Czajka J, Irvin C, Coupé W, Quinn B. Implementation of the State Children's Health Insurance Program: Momentum is increasing after a 
modest start. First annual report to the Health Care Financing Administration. Mathematica Policy Research Inc.: Cambridge, MA; 2001.

Schenker N, Trivellore E, Raghunathan P-LC, Makuc DM, Zhang G, Cohen AJ. Multiple imputation of missing income data in the National Health Interview Survey. Journal of the American Statistical Association 2006; 101 (475); 924-933.

U. S. Committee on Ways and Means. House of Representatives (1993) Overview of entitlement programs: 1993 Green book. US Government Printing Office: Washington DC; 1993.

U.S. Bureau of the Census. People in families with related children under 18 by family structure, age, sex, iterated by income-to-poverty ratio and race. U.S. Census: Washington DC; 2004.

Williams RL. A note on robust variance estimation for cluster-correlated data. Biometrics 2000; 56; 645-646. 


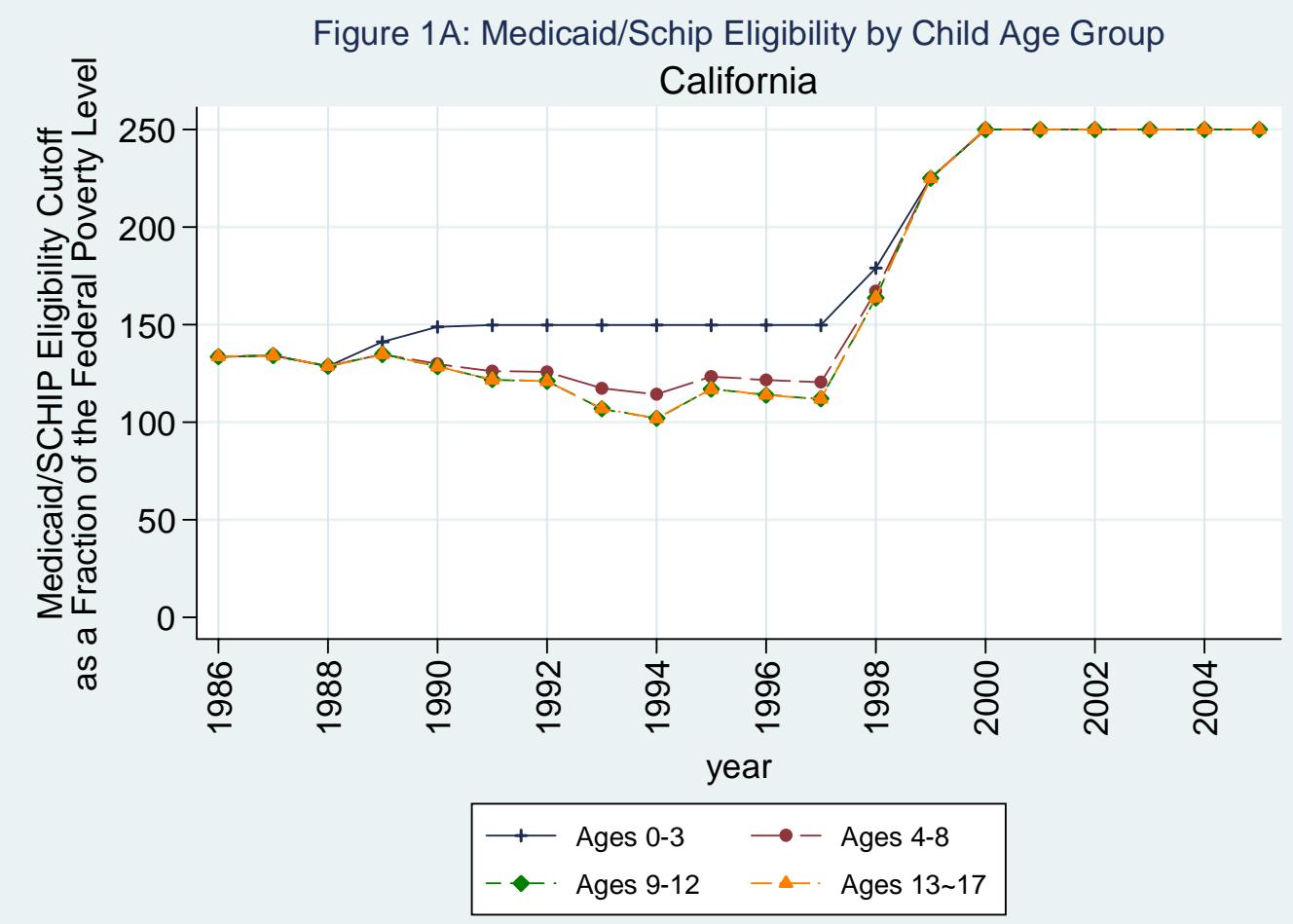

Figure 1B: Medicaid/Schip Eligibility by Child Age Group

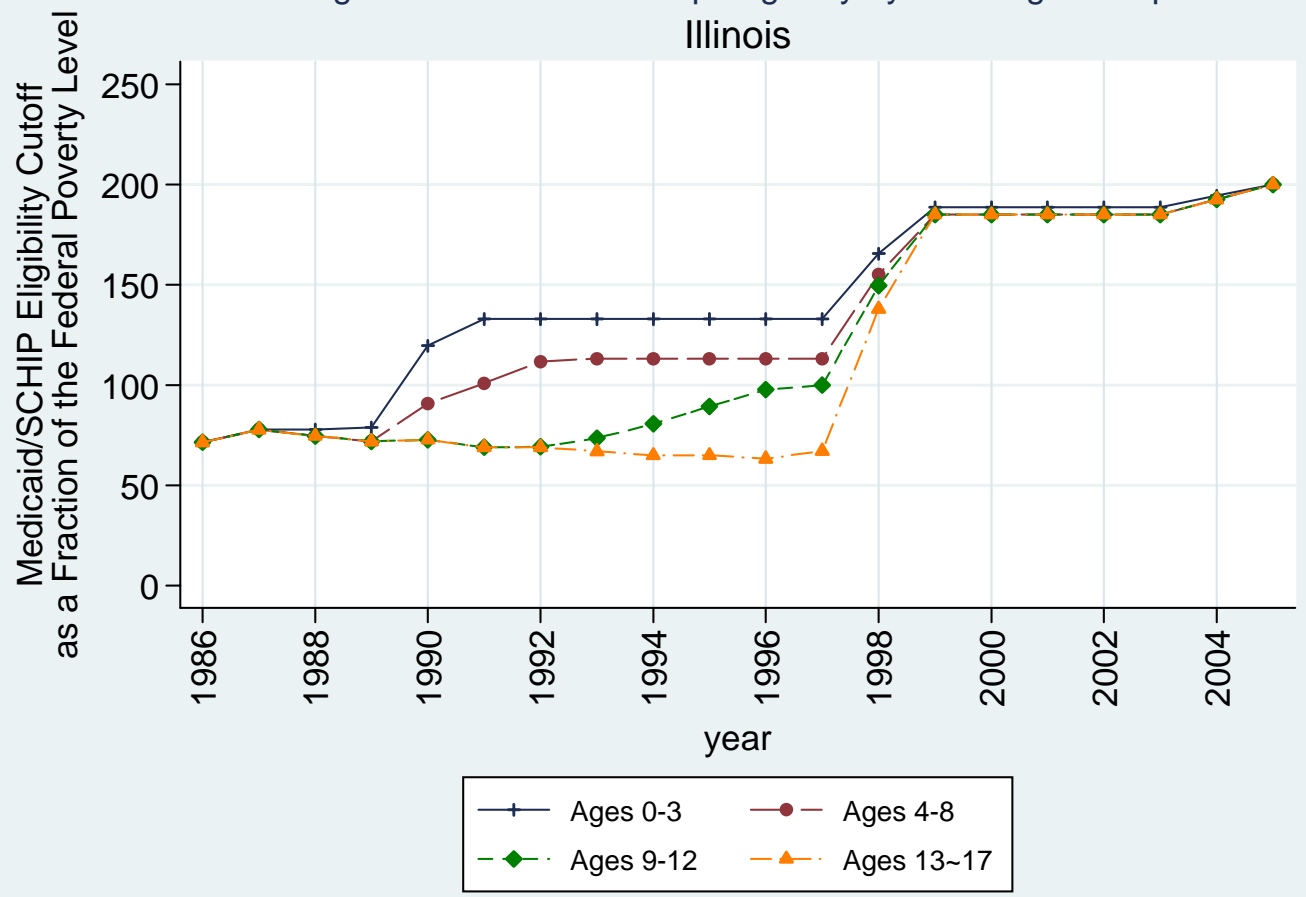




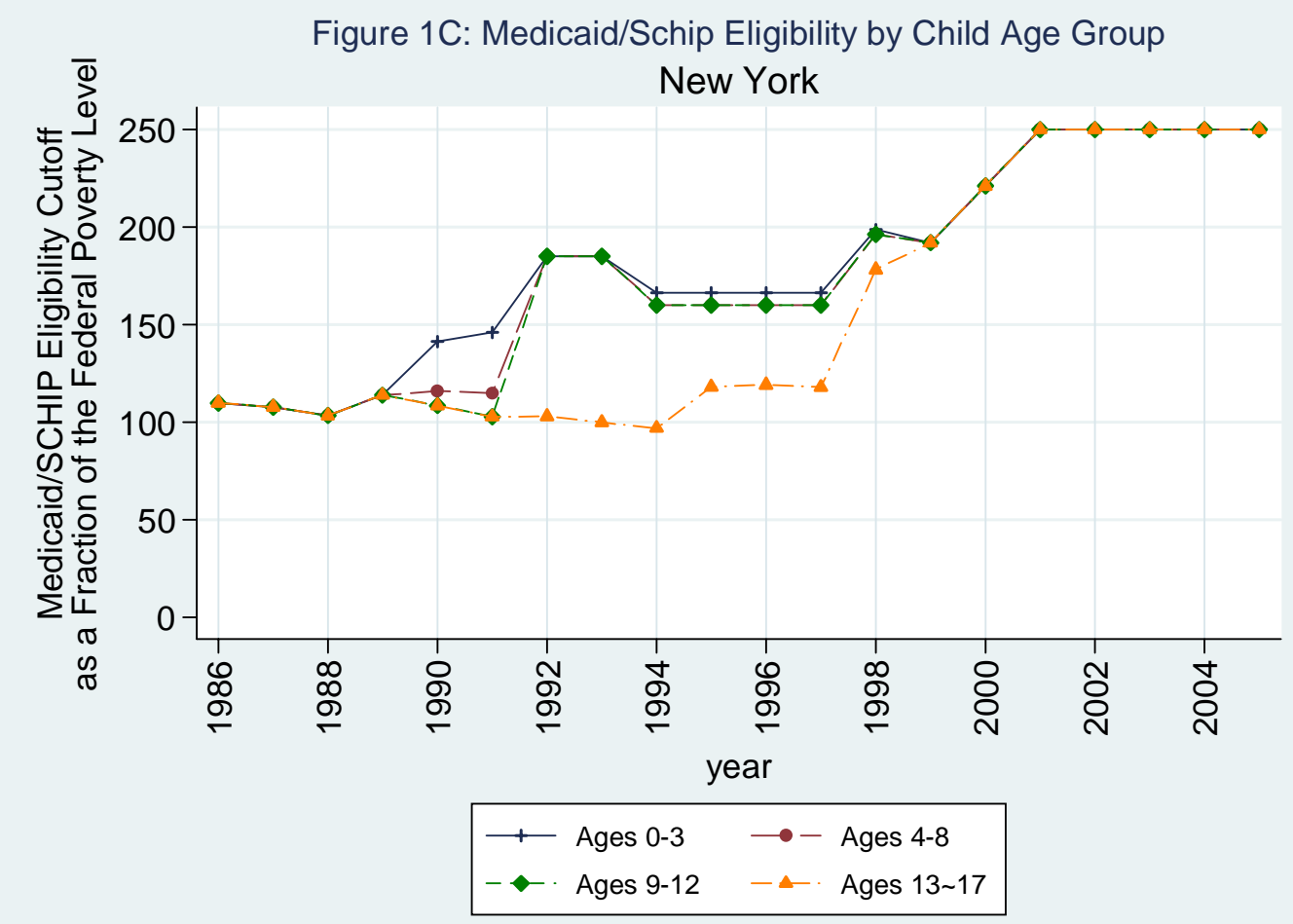

Figure 1D: Medicaid/Schip Eligibility by Child Age Group

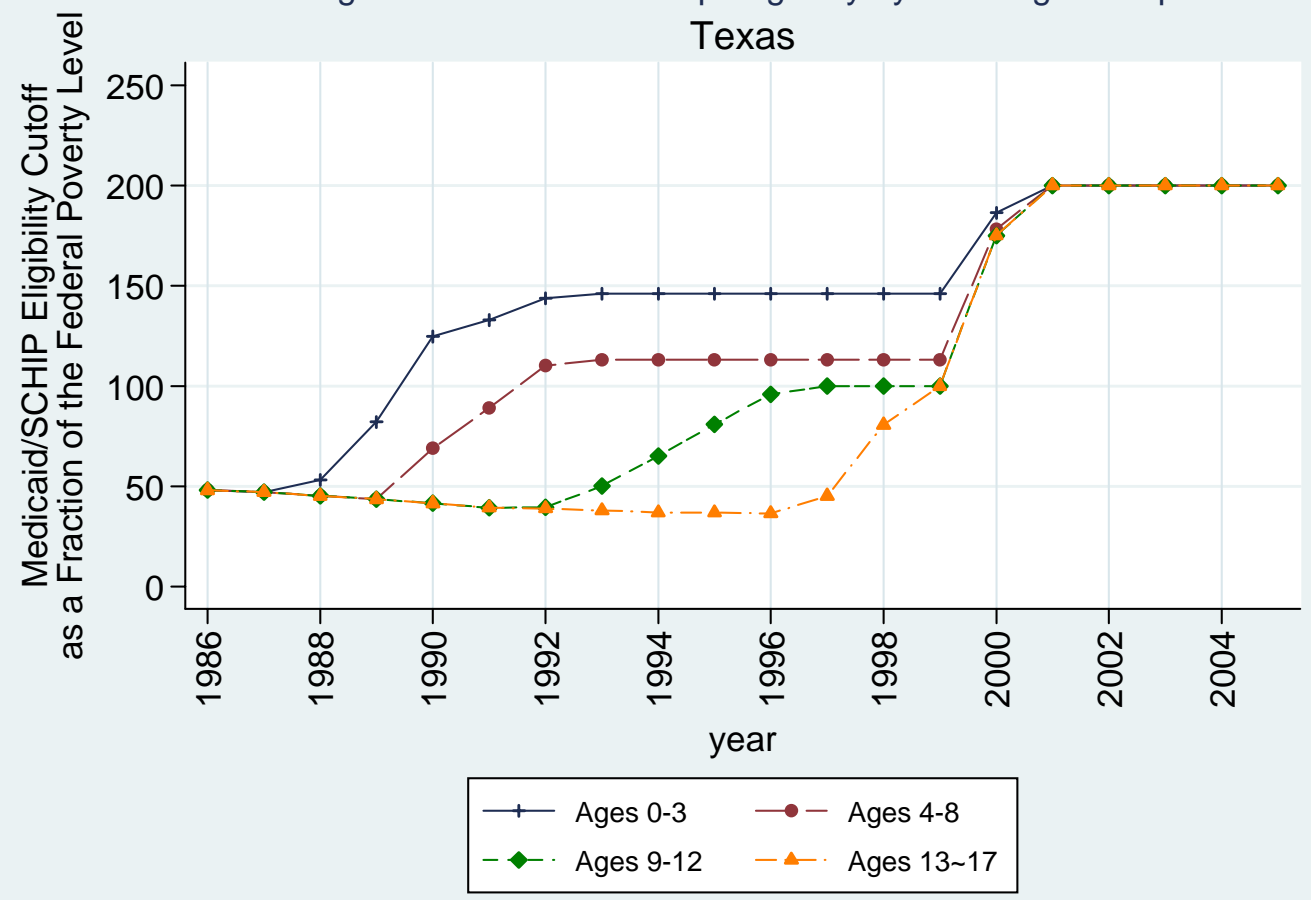


Figure 2: Overall Increase in Public Health Insurance Over Time

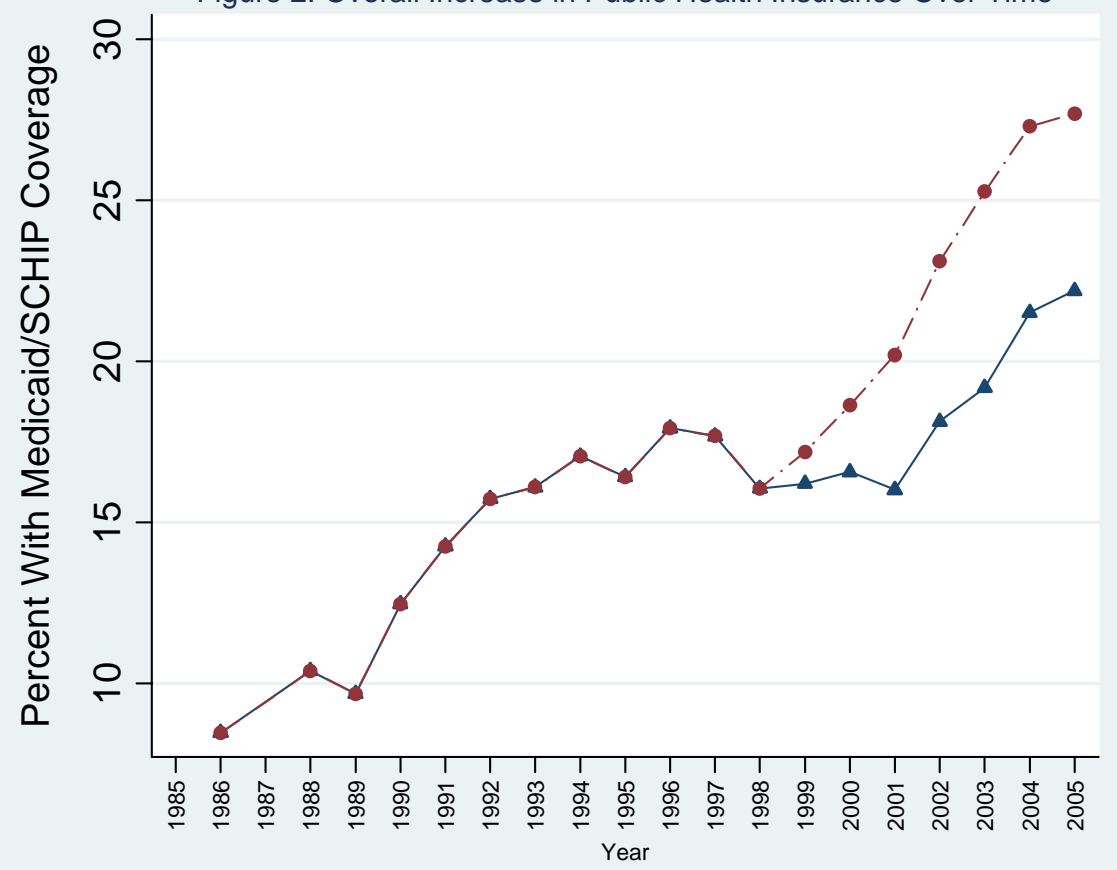

$\multimap$ Medicaid Enrollments $\bullet-$ Medicaid + SCHIP Enrollments

Calculated from the final NHIS sample used in this paper. No SCHIP Enrollment Information Prior to 1999

Figure 3: Health Status ( $1=$ excellent to $5=$ poor)
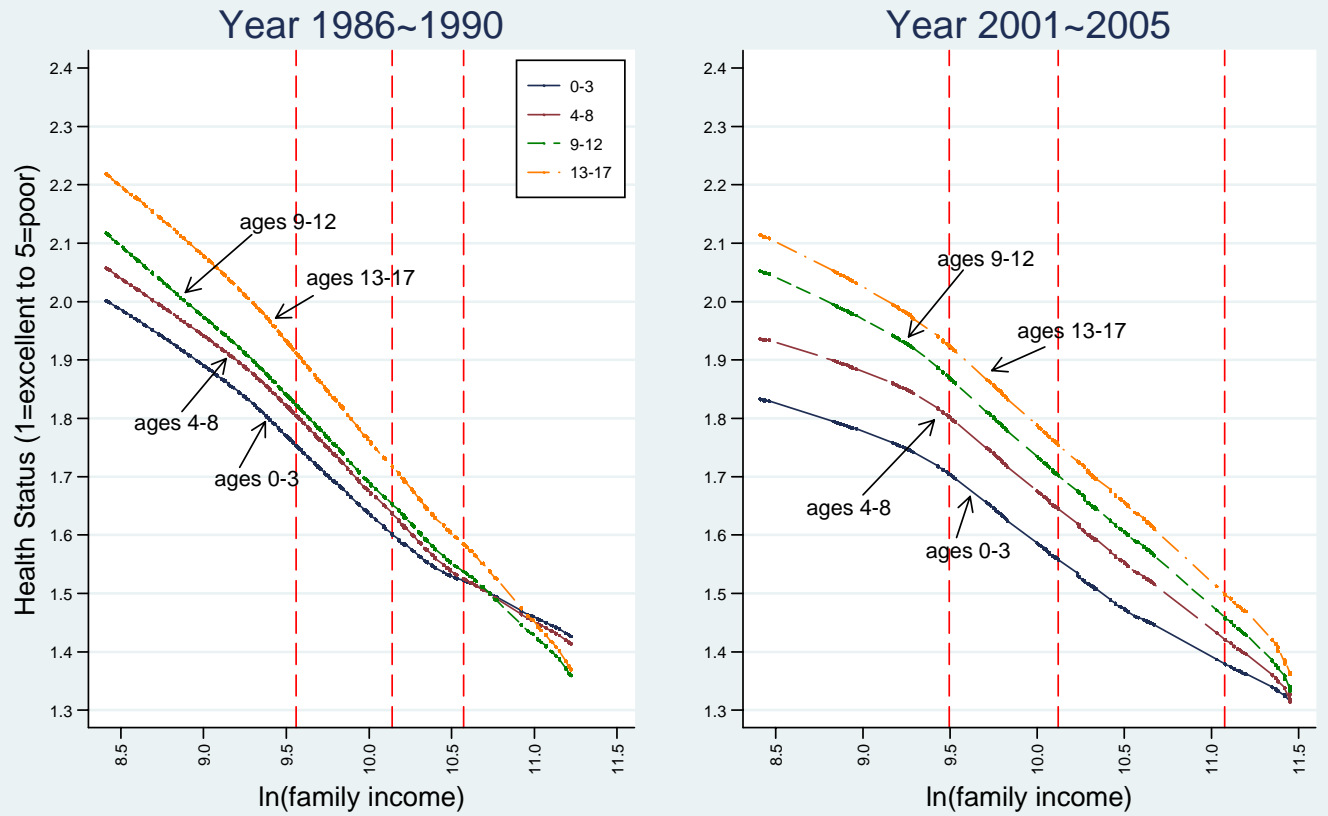

The vertical lines in the figures are placed at the 25 th, 50 th and 75 th percentiles of income. 


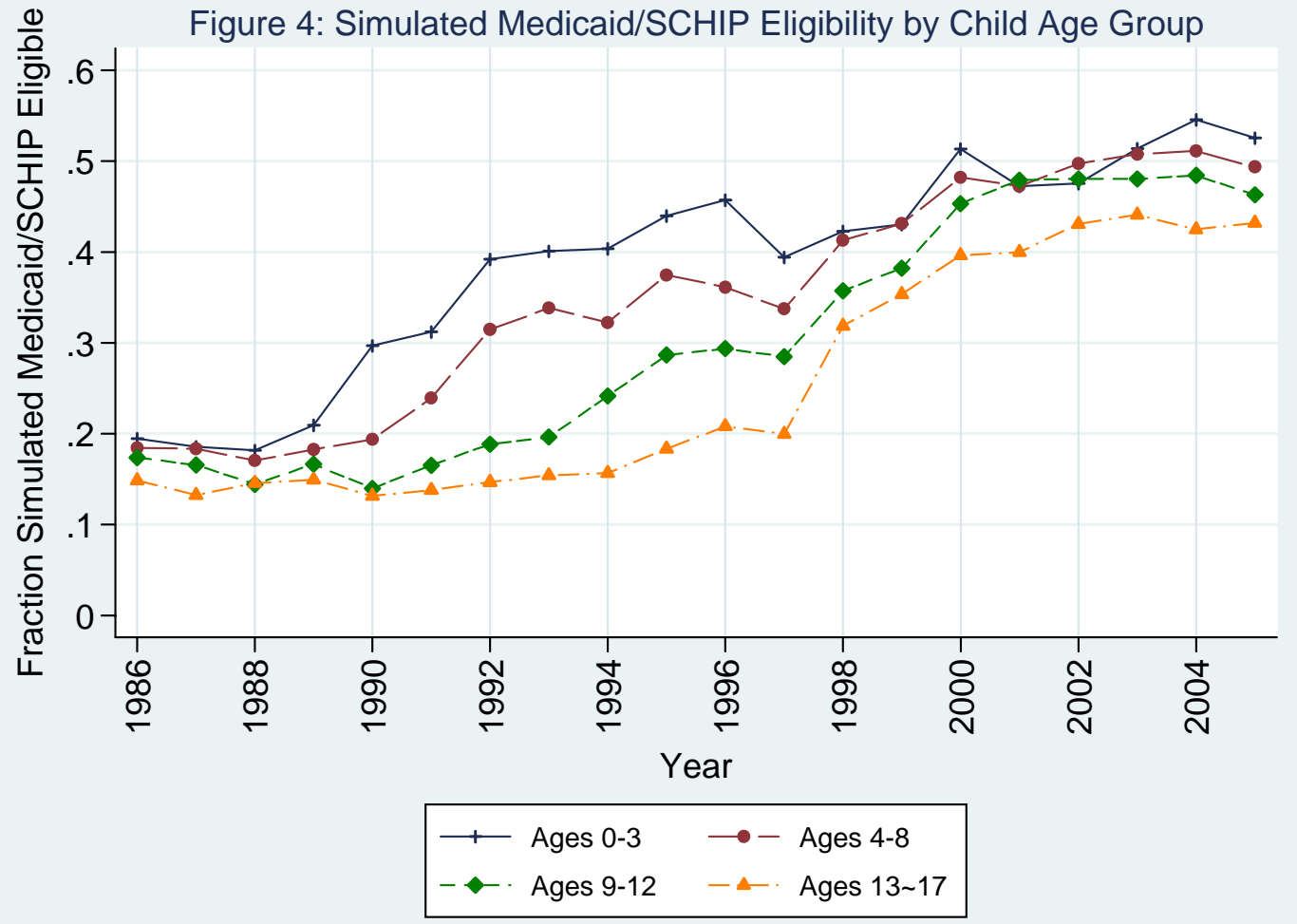


Table 1: Medicaid/SCHIP Income Eligibility Cutoff

\begin{tabular}{|c|c|c|c|c|}
\hline Year & Ages $0-3$ & Ages 4-8 & Ages $9-12$ & Ages $13-17$ \\
\hline 1986 & 85 & 85 & 84 & 84 \\
\hline 1987 & 88 & 87 & 86 & 86 \\
\hline 1988 & 92 & 86 & 85 & 85 \\
\hline 1989 & 104 & 88 & 87 & 87 \\
\hline 1990 & 133 & 102 & 84 & 84 \\
\hline 1991 & 142 & 109 & 81 & 81 \\
\hline 1992 & 146 & 121 & 86 & 80 \\
\hline 1993 & 153 & 126 & 94 & 83 \\
\hline 1994 & 153 & 128 & 101 & 84 \\
\hline 1995 & 154 & 132 & 114 & 92 \\
\hline 1996 & 155 & 132 & 121 & 94 \\
\hline 1997 & 156 & 134 & 124 & 100 \\
\hline 1998 & 179 & 167 & 162 & 155 \\
\hline 1999 & 196 & 192 & 189 & 187 \\
\hline 2000 & 211 & 211 & 211 & 209 \\
\hline 2001 & 219 & 219 & 220 & 218 \\
\hline 2002 & 219 & 220 & 221 & 219 \\
\hline 2003 & 220 & 219 & 220 & 219 \\
\hline 2004 & 220 & 219 & 220 & 219 \\
\hline 2005 & 221 & 220 & 220 & 220 \\
\hline
\end{tabular}

Note: This table reports the mean eligibility cutoffs across states weighted by 
Table 2: Mean Charaacteristics of the NHIS Sample by Child Age Group and Time Period

\begin{tabular}{|c|c|c|c|c|c|}
\hline 1986-1995 & All & Ages $0-3$ & Ages 4-8 & Ages 9-12 & Ages 13-17 \\
\hline \multicolumn{6}{|l|}{ Child Characteristics } \\
\hline Parent-Assessed Health (Excellent = 1 to Poor $=5$ ) & 1.69 & 1.66 & 1.68 & 1.68 & 1.72 \\
\hline Parent-Assessed Health for Children Under Poverty & 2.03 & 1.97 & 2.00 & 2.04 & 2.15 \\
\hline Less Than Excellent Health & 0.47 & 0.45 & 0.47 & 0.46 & 0.48 \\
\hline Less Than Excellent Health for Children Under Poverty & 0.62 & 0.59 & 0.61 & 0.63 & 0.66 \\
\hline No Doctor Visit in the Past Year & 0.20 & 0.07 & 0.17 & 0.28 & 0.27 \\
\hline No Doctor Visit in the Past Year for Children Under Poverty & 0.25 & 0.10 & 0.22 & 0.34 & 0.36 \\
\hline Family Income (1986 Dollars) & 29,726 & 27,579 & 28,981 & 30,284 & 31,805 \\
\hline Family Size & 4.4 & 4.1 & 4.4 & 4.5 & 4.4 \\
\hline No Mom Present & 0.01 & 0.01 & 0.01 & 0.02 & 0.02 \\
\hline No Dad Present & 0.20 & 0.17 & 0.20 & 0.21 & 0.22 \\
\hline Male & 0.51 & 0.51 & 0.51 & 0.51 & 0.52 \\
\hline Non-Hispanic Black & 0.14 & 0.13 & 0.14 & 0.14 & 0.14 \\
\hline Hispanic & 0.12 & 0.13 & 0.12 & 0.12 & 0.11 \\
\hline Non-Hispanic Other Race & 0.04 & 0.04 & 0.04 & 0.04 & 0.04 \\
\hline \multicolumn{6}{|l|}{ Parent Characteristics (If Parent Present) } \\
\hline Mom's Age (Years) & 35.0 & 29.4 & 32.9 & 36.5 & 40.5 \\
\hline Dad's Age (Years) & 37.8 & 32.2 & 35.7 & 39.3 & 43.4 \\
\hline Mom Has Less Than 12 Years of Education & 0.18 & 0.17 & 0.17 & 0.18 & 0.19 \\
\hline Mom Has 12 Years of Education & 0.41 & 0.39 & 0.41 & 0.42 & 0.43 \\
\hline Dad Has Less Than 12 Years of Education & 0.16 & 0.15 & 0.15 & 0.17 & 0.18 \\
\hline Dad Has 12 Years of Education & 0.36 & 0.37 & 0.37 & 0.36 & 0.36 \\
\hline Mom Unemployed & 0.04 & 0.05 & 0.04 & 0.04 & 0.03 \\
\hline Dad Unemployed & 0.03 & 0.04 & 0.03 & 0.03 & 0.03 \\
\hline Observations & 265,611 & 57,206 & 76,687 & 60,329 & 71,389 \\
\hline
\end{tabular}

1996-2005

\section{Child Characteristics}

Parent-Assessed Health (Excellent $=1$ to Poor $=5$ )

Parent-Assessed Health for Children Under Poverty

Less Than Excellent Health

Less Than Excellent Health for Children Under Poverty

No Doctor Visit in the Past Year*

No Doctor Visit in the Past Year for Children Under Poverty

Family Income (1986 Dollars)

Family Size

No Mom Present

No Dad Present

Male

Non-Hispanic Black

Hispanic

Non-Hispanic Other Race

Parent Characteristics (If Parent Present)

Mom's Age (Years)

Dad's Age (Years)

Mom Has Less Than 12 Years of Education

Mom Has 12 Years of Education

Dad Has Less Than 12 Years of Education

Dad Has 12 Years of Education

Mom Unemployed

Dad Unemployed

Observations

$\begin{array}{ccccc}1.62 & 1.54 & 1.60 & 1.63 & 1.67 \\ 1.93 & 1.82 & 1.91 & 1.98 & 2.04 \\ 0.44 & 0.40 & 0.43 & 0.45 & 0.47 \\ 0.59 & 0.50 & 0.57 & 0.61 & 0.63 \\ 0.13 & 0.06 & 0.11 & 0.17 & 0.17 \\ 0.17 & 0.08 & 0.15 & 0.42 & 0.25 \\ 38,215 & 35,961 & 37,315 & 38,943 & 40,253 \\ 4.3 & 4.1 & 4.4 & 4.5 & 4.3 \\ 0.03 & 0.01 & 0.02 & 0.03 & 0.04 \\ 0.20 & 0.17 & 0.20 & 0.22 & 0.23 \\ 0.51 & 0.51 & 0.51 & 0.51 & 0.52 \\ 0.13 & 0.12 & 0.13 & 0.14 & 0.13 \\ 0.16 & 0.18 & 0.16 & 0.15 & 0.14 \\ 0.05 & 0.06 & 0.05 & 0.05 & 0.05 \\ & & & & \\ 36.0 & 30.1 & 33.8 & 37.6 & 41.4 \\ 38.6 & 32.9 & 36.7 & 40.3 & 44.0 \\ 0.14 & 0.14 & 0.14 & 0.13 & 0.13 \\ 0.31 & 0.28 & 0.30 & 0.31 & 0.33 \\ 0.13 & 0.13 & 0.13 & 0.13 & 0.13 \\ 0.31 & 0.29 & 0.30 & 0.31 & 0.32 \\ 0.03 & 0.03 & 0.03 & 0.03 & 0.02 \\ 0.02 & 0.02 & 0.02 & 0.02 & 0.02 \\ 208,553 & 43,699 & 59,598 & 48,475 & 56,781 \\ & & & & \end{array}$

* For 1996-2005, the number of observations for this variable is 111,278 for all ages and 25,451, 29,722, 23,973 and 32,132 for ages 0-3, 4-8, 9-12 and 1317 respectively. The survey question about doctor visits was asked only of some (sample) children beginning in 1997. 
Table 3: The Effect of Income on Child Health

Ordered Probit (1=Excellent, 2=Very Good, 3=Good, 4=Fair, 5=Poor)

\begin{tabular}{|c|c|c|c|c|}
\hline & Ages 0-3 & Ages 4-8 & Ages 9-12 & Ages 13-17 \\
\hline \multirow[t]{2}{*}{ Log Family Income (\$1986) } & -0.136 & -0.155 & -0.193 & -0.219 \\
\hline & {$[0.011]^{* * *}$} & {$[0.010]^{* * *}$} & {$[0.010]^{* * *}$} & {$[0.011]^{* * *}$} \\
\hline \multirow[t]{2}{*}{ * 1991-1995 Time Period } & 0.002 & -0.008 & 0.005 & 0.014 \\
\hline & {$[0.013]$} & {$[0.012]$} & {$[0.014]$} & [0.015] \\
\hline \multirow[t]{2}{*}{ * 1996-2000 Time Period } & -0.006 & -0.02 & 0.007 & 0.043 \\
\hline & {$[0.014]$} & [0.013] & {$[0.014]$} & {$[0.014]^{* * *}$} \\
\hline \multirow[t]{2}{*}{ * 2000-2005 Time Period } & 0.022 & 0.027 & 0.039 & 0.055 \\
\hline & {$[0.013]$} & {$[0.013]^{* *}$} & {$[0.013]^{* * *}$} & {$[0.013]^{* * *}$} \\
\hline \multirow[t]{2}{*}{ Log of Family Size } & 0.218 & 0.049 & 0.024 & 0.013 \\
\hline & {$[0.018]^{* * *}$} & {$[0.017]^{* * *}$} & [0.017] & [0.015] \\
\hline \multirow[t]{2}{*}{ No Mom Present } & 0.158 & 0.143 & 0.139 & 0.136 \\
\hline & {$[0.052]^{* * *}$} & {$[0.044]^{* * *}$} & {$[0.044]^{* * *}$} & {$[0.043]^{* * *}$} \\
\hline \multirow[t]{2}{*}{ No Dad Present } & 0.187 & 0.155 & 0.117 & 0.155 \\
\hline & {$[0.033]^{* * *}$} & {$[0.032]^{* * *}$} & {$[0.036]^{* * *}$} & {$[0.036]^{* * *}$} \\
\hline \multirow[t]{2}{*}{ Male } & 0.056 & 0.04 & 0.025 & -0.077 \\
\hline & {$[0.008]^{* * *}$} & {$[0.007]^{* * *}$} & {$[0.008]^{* * *}$} & {$[0.007]^{* * *}$} \\
\hline \multirow[t]{2}{*}{ Non-Hispanic Black } & 0.142 & 0.192 & 0.246 & 0.242 \\
\hline & {$[0.016]^{* * *}$} & {$[0.014]^{* * *}$} & {$[0.014]^{* * *}$} & {$[0.013]^{* * *}$} \\
\hline \multirow[t]{2}{*}{ Hispanic } & 0.152 & 0.159 & 0.152 & 0.121 \\
\hline & {$[0.013]^{* * *}$} & {$[0.013]^{* * *}$} & {$[0.014]^{* * *}$} & {$[0.014]^{* * *}$} \\
\hline \multirow[t]{2}{*}{ Non-Hispanic Other Race } & 0.153 & 0.218 & 0.164 & 0.124 \\
\hline & {$[0.022]^{* * *}$} & {$[0.019]^{* * *}$} & {$[0.022]^{* * *}$} & {$[0.021]^{* * *}$} \\
\hline \multirow[t]{2}{*}{ Mom's Age } & 0.002 & 0.003 & 0.001 & 0.001 \\
\hline & {$[0.001]$} & {$[0.001]^{* * *}$} & {$[0.001]$} & {$[0.001]$} \\
\hline \multirow[t]{2}{*}{ Mom Has Less Than 12 Years of Education } & -0.001 & -0.001 & -0.001 & 0 \\
\hline & {$[0.001]$} & {$[0.001]$} & {$[0.001]$} & {$[0.001]$} \\
\hline \multirow[t]{2}{*}{ Mom Has 12 Years of Education } & 0.229 & 0.297 & 0.321 & 0.3 \\
\hline & {$[0.017]^{* * *}$} & {$[0.015]^{* * *}$} & {$[0.016]^{* * *}$} & {$[0.014]^{* * *}$} \\
\hline \multirow[t]{2}{*}{ Mom Unemployed } & 0.109 & 0.153 & 0.157 & 0.151 \\
\hline & {$[0.012]^{* * *}$} & {$[0.010]^{* * *}$} & {$[0.011]^{* * *}$} & {$[0.010]^{* * *}$} \\
\hline \multirow[t]{2}{*}{ Dad's Age } & 0.253 & 0.274 & 0.26 & 0.297 \\
\hline & {$[0.017]^{* * *}$} & {$[0.016]^{* * *}$} & {$[0.017]^{* * *}$} & {$[0.016]^{* * *}$} \\
\hline \multirow[t]{2}{*}{ Dad Has Less Than 12 Years of Education } & 0.136 & 0.152 & 0.143 & 0.158 \\
\hline & {$[0.012]^{* * *}$} & {$[0.011]^{* * *}$} & {$[0.012]^{* * *}$} & {$[0.011]^{* * *}$} \\
\hline \multirow[t]{2}{*}{ Dad Has 12 Years of Education } & -0.016 & 0.042 & -0.043 & 0.04 \\
\hline & [0.025] & {$[0.023]^{*}$} & {$[0.024]^{*}$} & {$[0.026]$} \\
\hline \multirow[t]{2}{*}{ Dad Unemployed } & 0.038 & 0.01 & -0.015 & 0.018 \\
\hline & {$[0.030]$} & {$[0.026]$} & {$[0.030]$} & {$[0.030]$} \\
\hline Observations & 100,905 & 136,285 & 108,804 & 128,170 \\
\hline
\end{tabular}

The table reports coefficients and standard errors (in brackets) from ordered probit models where the dependent variable is child self-reported health. Although not reported, controls include year, age and state effects. ${ }^{*}$ significant at $10 \%$, ${ }^{* *}$ significant at $5 \%, * * *$ significant at $1 \%$. 
Table 4: The Effect of Income on Child Health

Linear Probability (Dependent Variable: Less Than Excellent Health)

\begin{tabular}{|c|c|c|c|c|}
\hline & Ages 0-3 & Ages 4-8 & Ages 9-12 & Ages $13-17$ \\
\hline \multirow[t]{2}{*}{ Log Family Income (\$1986) } & -0.045 & -0.053 & -0.066 & -0.075 \\
\hline & {$[0.004]^{* * *}$} & {$[0.004]^{* * *}$} & {$[0.004]^{* * *}$} & {$[0.004]^{* * *}$} \\
\hline \multirow[t]{2}{*}{ * 1991-1995 Time Period } & -0.003 & -0.004 & 0 & 0.005 \\
\hline & {$[0.005]$} & {$[0.005]$} & {$[0.005]$} & {$[0.006]$} \\
\hline \multirow[t]{2}{*}{ * 1996-2000 Time Period } & -0.005 & -0.009 & 0.003 & 0.015 \\
\hline & {$[0.006]$} & {$[0.005]^{*}$} & {$[0.006]$} & {$[0.006]^{* *}$} \\
\hline \multirow[t]{2}{*}{ * 2000-2005 Time Period } & 0.007 & 0.008 & 0.013 & 0.017 \\
\hline & {$[0.006]$} & {$[0.005]$} & {$[0.006]^{* *}$} & {$[0.006]^{* * *}$} \\
\hline \multirow[t]{2}{*}{ Log of Family Size } & 0.069 & 0.01 & -0.001 & -0.001 \\
\hline & {$[0.008]^{* * *}$} & [0.007] & {$[0.007]$} & {$[0.007]$} \\
\hline \multirow[t]{2}{*}{ No Mom Present } & 0.044 & 0.035 & 0.029 & 0.046 \\
\hline & {$[0.021]^{* *}$} & {$[0.018]^{*}$} & {$[0.018]$} & {$[0.019]^{* *}$} \\
\hline \multirow[t]{2}{*}{ No Dad Present } & 0.058 & 0.048 & 0.027 & 0.038 \\
\hline & {$[0.014]^{* * *}$} & {$[0.014]^{* * *}$} & {$[0.015]^{*}$} & {$[0.016]^{* *}$} \\
\hline \multirow[t]{2}{*}{ Male } & 0.018 & 0.013 & 0.007 & -0.03 \\
\hline & {$[0.003]^{* * *}$} & {$[0.003]^{* * *}$} & {$[0.003]^{* *}$} & {$[0.003]^{* * *}$} \\
\hline \multirow[t]{2}{*}{ Non-Hispanic Black } & 0.041 & 0.057 & 0.08 & 0.084 \\
\hline & {$[0.007]^{* * *}$} & {$[0.006]^{* * *}$} & {$[0.006]^{* * *}$} & {$[0.006]^{* * *}$} \\
\hline \multirow[t]{2}{*}{ Hispanic } & 0.056 & 0.058 & 0.058 & 0.043 \\
\hline & {$[0.006]^{* * *}$} & {$[0.006]^{* * *}$} & {$[0.006]^{* * *}$} & {$[0.006]^{* * *}$} \\
\hline \multirow[t]{2}{*}{ Non-Hispanic Other Race } & 0.058 & 0.079 & 0.063 & 0.049 \\
\hline & {$[0.009]^{* * *}$} & {$[0.008]^{* * *}$} & {$[0.010]^{* * *}$} & {$[0.009]^{* * *}$} \\
\hline \multirow[t]{2}{*}{ Mom's Age } & 0.001 & 0.001 & 0 & 0 \\
\hline & {$[0.000]$} & {$[0.000]$} & {$[0.000]$} & {$[0.000]$} \\
\hline \multirow[t]{2}{*}{ Mom Has Less Than 12 Years of Education } & -0.001 & 0 & -0.001 & -0.001 \\
\hline & {$[0.000]^{*}$} & {$[0.000]$} & {$[0.000]^{*}$} & {$[0.000]^{*}$} \\
\hline \multirow[t]{2}{*}{ Mom Has 12 Years of Education } & 0.077 & 0.103 & 0.111 & 0.099 \\
\hline & {$[0.007]^{* * *}$} & {$[0.007]^{* * *}$} & {$[0.007]^{* * *}$} & {$[0.006]^{* * *}$} \\
\hline \multirow[t]{2}{*}{ Mom Unemployed } & 0.042 & 0.06 & 0.058 & 0.061 \\
\hline & {$[0.005]^{* * *}$} & {$[0.004]^{* * *}$} & {$[0.005]^{* * *}$} & {$[0.004]^{* * *}$} \\
\hline \multirow[t]{2}{*}{ Dad's Age } & 0.098 & 0.103 & 0.097 & 0.115 \\
\hline & {$[0.007]^{* * *}$} & {$[0.007]^{* * *}$} & {$[0.007]^{* * *}$} & {$[0.007]^{* * *}$} \\
\hline \multirow[t]{2}{*}{ Dad Has Less Than 12 Years of Education } & 0.05 & 0.058 & 0.056 & 0.066 \\
\hline & {$[0.005]^{* * *}$} & {$[0.005]^{* * *}$} & {$[0.005]^{* * *}$} & {$[0.005]^{* * *}$} \\
\hline \multirow[t]{2}{*}{ Dad Has 12 Years of Education } & -0.01 & 0.016 & -0.015 & 0.007 \\
\hline & {$[0.010]$} & {$[0.010]^{*}$} & {$[0.010]$} & {$[0.011]$} \\
\hline \multirow[t]{2}{*}{ Dad Unemployed } & 0.008 & -0.001 & -0.016 & 0.01 \\
\hline & [0.013] & [0.011] & [0.013] & [0.013] \\
\hline Observations & 100,905 & 136,285 & 108,804 & 128,170 \\
\hline R-squared & 0.051 & 0.055 & 0.058 & 0.061 \\
\hline
\end{tabular}

The table reports coefficients and standard errors (in brackets) from linear probability models estimating the probability that a child is in less than excellent health. Although not reported, controls include year, age and state effects. * significant at $10 \%, * *$ significant at $5 \%,{ }^{* * *}$ significant at $1 \%$. 
Table 5: The Effect of Income on Children's Access to Health Care

Linear Probability (Dependent Variable: No Doctor Visit in the Past Year)

\begin{tabular}{|c|c|c|c|c|}
\hline & Ages 0-3 & Ages 4-8 & Ages 9-12 & Ages 13-17 \\
\hline Log Family Income (\$1986 Dollars) & $\begin{array}{c}-0.014 \\
{[0.003]^{* * *}}\end{array}$ & $\begin{array}{c}-0.037 \\
{[0.003]^{* * *}}\end{array}$ & $\begin{array}{c}-0.041 \\
{[0.005]^{* * *}}\end{array}$ & $\begin{array}{c}-0.036 \\
{[0.004]^{* * *}}\end{array}$ \\
\hline * 1991-1995 Time Period & $\begin{array}{c}0.006 \\
{[0.003]^{* *}}\end{array}$ & $\begin{array}{c}0.015 \\
{[0.003]^{* * *}}\end{array}$ & $\begin{array}{c}0.01 \\
{[0.005]^{* *}}\end{array}$ & $\begin{array}{c}-0.002 \\
{[0.005]}\end{array}$ \\
\hline * 1996-2000 Time Period & $\begin{array}{c}0.008 \\
{[0.004]^{* *}}\end{array}$ & $\begin{array}{c}0.016 \\
{[0.004]^{* * *}}\end{array}$ & $\begin{array}{c}0.008 \\
{[0.006]}\end{array}$ & $\begin{array}{c}0.004 \\
{[0.006]}\end{array}$ \\
\hline * 2000-2005 Time Period & $\begin{array}{c}0.009 \\
{[0.003]^{* * *}}\end{array}$ & $\begin{array}{c}0.023 \\
{[0.005]^{* * *}}\end{array}$ & $\begin{array}{c}0.021 \\
{[0.006]^{* * *}}\end{array}$ & $\begin{array}{c}0.01 \\
{[0.006]^{*}}\end{array}$ \\
\hline Log of Family Size & $\begin{array}{c}0.037 \\
{[0.005]^{* * *}}\end{array}$ & $\begin{array}{c}0.092 \\
{[0.006]^{* * *}}\end{array}$ & $\begin{array}{c}0.094 \\
{[0.008]^{* * *}}\end{array}$ & $\begin{array}{c}0.062 \\
{[0.007]^{* * *}}\end{array}$ \\
\hline No Mom Present & $\begin{array}{c}0.039 \\
{[0.014]^{* * *}}\end{array}$ & $\begin{array}{c}0.084 \\
{[0.015]^{* * *}}\end{array}$ & $\begin{array}{c}0.084 \\
{[0.020]^{* * *}}\end{array}$ & $\begin{array}{c}0.099 \\
{[0.018]^{* * *}}\end{array}$ \\
\hline No Dad Present & $\begin{array}{c}-0.001 \\
{[0.009]}\end{array}$ & $\begin{array}{c}-0.021 \\
{[0.011]^{*}}\end{array}$ & $\begin{array}{c}-0.044 \\
{[0.016]^{* * *}}\end{array}$ & $\begin{array}{c}-0.013 \\
{[0.015]}\end{array}$ \\
\hline Male & $\begin{array}{c}-0.003 \\
{[0.002]}\end{array}$ & $\begin{array}{c}0.003 \\
{[0.002]}\end{array}$ & $\begin{array}{c}0.002 \\
{[0.004]}\end{array}$ & $\begin{array}{c}0.017 \\
{[0.003]^{* * *}}\end{array}$ \\
\hline Non-Hispanic Black & $\begin{array}{c}0.014 \\
{[0.004]^{* * *}}\end{array}$ & $\begin{array}{c}0.026 \\
{[0.005]^{* * *}}\end{array}$ & $\begin{array}{c}0.031 \\
{[0.006]^{* * *}}\end{array}$ & $\begin{array}{c}0.038 \\
{[0.006]^{* * *}}\end{array}$ \\
\hline Hispanic & $\begin{array}{c}0.014 \\
{[0.004]^{* * *}}\end{array}$ & $\begin{array}{c}0.024 \\
{[0.005]^{* * *}}\end{array}$ & $\begin{array}{c}0.045 \\
{[0.006]^{* * *}}\end{array}$ & $\begin{array}{c}0.071 \\
{[0.005]^{* * *}}\end{array}$ \\
\hline Non-Hispanic Other Race & $\begin{array}{c}0.018 \\
{[0.006]^{* * *}}\end{array}$ & $\begin{array}{c}0.035 \\
{[0.008]^{* * *}}\end{array}$ & $\begin{array}{c}0.052 \\
{[0.011]^{* * *}}\end{array}$ & $\begin{array}{c}0.09 \\
{[0.009]^{* * *}}\end{array}$ \\
\hline Mom's Age & $\begin{array}{c}0 \\
{[0.000]}\end{array}$ & $\begin{array}{c}0.001 \\
{[0.000]^{*}}\end{array}$ & $\begin{array}{c}0 \\
{[0.000]}\end{array}$ & $\begin{array}{c}0 \\
{[0.000]}\end{array}$ \\
\hline Mom Has Less Than 12 Years of Education & $\begin{array}{c}0 \\
{[0.000]}\end{array}$ & $\begin{array}{c}-0.001 \\
{[0.000]^{*}}\end{array}$ & $\begin{array}{c}-0.001 \\
{[0.000]^{* *}}\end{array}$ & $\begin{array}{c}0 \\
{[0.000]}\end{array}$ \\
\hline Mom Has 12 Years of Education & $\begin{array}{c}0.029 \\
{[0.004]^{* * *}}\end{array}$ & $\begin{array}{c}0.046 \\
{[0.006]^{* * *}}\end{array}$ & $\begin{array}{c}0.056 \\
{[0.007]^{* * *}}\end{array}$ & $\begin{array}{c}0.078 \\
{[0.006]^{* * *}}\end{array}$ \\
\hline Mom Unemployed & $\begin{array}{c}0.014 \\
{[0.003]^{* * *}}\end{array}$ & $\begin{array}{c}0.022 \\
{[0.004]^{* * *}}\end{array}$ & $\begin{array}{c}0.028 \\
{[0.004]^{* * *}}\end{array}$ & $\begin{array}{c}0.037 \\
{[0.004]^{* * *}}\end{array}$ \\
\hline Dad's Age & $\begin{array}{c}0.037 \\
{[0.006]^{* * *}}\end{array}$ & $\begin{array}{c}0.053 \\
{[0.006]^{* * *}}\end{array}$ & $\begin{array}{c}0.065 \\
{[0.007]^{* * *}}\end{array}$ & $\begin{array}{c}0.069 \\
{[0.006]^{* * *}}\end{array}$ \\
\hline Dad Has Less Than 12 Years of Education & $\begin{array}{c}0.013 \\
{[0.003]^{* * *}}\end{array}$ & $\begin{array}{c}0.023 \\
{[0.004]^{* * *}}\end{array}$ & $\begin{array}{c}0.036 \\
{[0.005]^{* * *}}\end{array}$ & $\begin{array}{c}0.033 \\
{[0.004]^{* * *}}\end{array}$ \\
\hline Dad Has 12 Years of Education & $\begin{array}{c}0.013 \\
{[0.006]^{* *}}\end{array}$ & $\begin{array}{c}-0.013 \\
{[0.008]^{*}}\end{array}$ & $\begin{array}{c}-0.013 \\
{[0.010]}\end{array}$ & $\begin{array}{c}-0.01 \\
{[0.009]}\end{array}$ \\
\hline Dad Unemployed & $\begin{array}{c}-0.01 \\
{[0.006]} \\
\end{array}$ & $\begin{array}{c}-0.011 \\
{[0.010]} \\
\end{array}$ & $\begin{array}{c}-0.015 \\
{[0.014]}\end{array}$ & $\begin{array}{c}0.015 \\
{[0.012]}\end{array}$ \\
\hline Observations & 82,657 & 106,409 & 84,302 & 103,521 \\
\hline R-squared & 0.026 & 0.045 & 0.048 & 0.056 \\
\hline
\end{tabular}

The table reports coefficients and standard errors (in brackets) from linear probability models estimating the probability that a child has had no doctor visit in the past year. Although not reported, controls include year, age and state effects. * significant at $10 \%$, ** significant at $5 \%$, ***significant at $1 \%$. 
Table 6: The Effect of Medicaid/SCHIP Eligibility on Child Health and Access to Health Care

Linear Probability Models

\begin{tabular}{|c|c|c|c|c|c|c|}
\hline \multirow[t]{2}{*}{ Dependent Variable: } & \multicolumn{3}{|c|}{ Less Than Excellent Health } & \multicolumn{3}{|c|}{ No Doctor Visit in the Past Year } \\
\hline & OLS & OLS & TSLS & OLS & OLS & TSLS \\
\hline Medicaid/SCHIP Eligible & & $\begin{array}{c}0.02 \\
{[0.004] * * *}\end{array}$ & $\begin{array}{c}-0.006 \\
{[0.020]}\end{array}$ & & $\begin{array}{c}-0.028 \\
{[0.003]^{* * *}}\end{array}$ & $\begin{array}{c}-0.068 \\
{[0.014]^{* * *}}\end{array}$ \\
\hline Log Family Income (\$1986) & $\begin{array}{c}-0.048 \\
{[0.002]^{* * *}}\end{array}$ & $\begin{array}{c}-0.041 \\
{[0.003] * * *}\end{array}$ & $\begin{array}{c}-0.05 \\
{[0.007]^{* * *}}\end{array}$ & $\begin{array}{c}-0.012 \\
{[0.002]^{* * *}}\end{array}$ & $\begin{array}{c}-0.021 \\
{[0.002]^{* * *}}\end{array}$ & $\begin{array}{c}-0.034 \\
{[0.005]^{* * *}}\end{array}$ \\
\hline Log Family Income (\$1986) * Ages 9-17 & $\begin{array}{c}-0.022 \\
{[0.003]^{* * *}}\end{array}$ & $\begin{array}{c}-0.023 \\
{[0.003]^{* * *}}\end{array}$ & $\begin{array}{c}-0.021 \\
{[0.003]^{* * *}}\end{array}$ & $\begin{array}{c}-0.026 \\
{[0.002]^{* * *}}\end{array}$ & $\begin{array}{c}-0.024 \\
{[0.002]^{* * *}}\end{array}$ & $\begin{array}{c}-0.021 \\
{[0.002]^{* * *}}\end{array}$ \\
\hline Log Family Income (\$1986) * 1996-2005 & $\begin{array}{c}0.002 \\
{[0.003]}\end{array}$ & $\begin{array}{c}0.003 \\
{[0.003]}\end{array}$ & $\begin{array}{c}0.002 \\
{[0.003]}\end{array}$ & $\begin{array}{c}0.007 \\
{[0.002]^{* * *}}\end{array}$ & $\begin{array}{c}0.006 \\
{[0.002]^{* * *}}\end{array}$ & $\begin{array}{c}0.005 \\
{[0.002]^{* *}}\end{array}$ \\
\hline Ages 9-17 * 1996-2005 & $\begin{array}{c}-0.047 \\
{[0.040]}\end{array}$ & $\begin{array}{c}-0.061 \\
{[0.040]}\end{array}$ & $\begin{array}{l}-0.043 \\
{[0.042]}\end{array}$ & $\begin{array}{c}-0.068 \\
{[0.034]^{* *}}\end{array}$ & $\begin{array}{c}-0.049 \\
{[0.034]}\end{array}$ & $\begin{array}{l}-0.022 \\
{[0.035]}\end{array}$ \\
\hline $\begin{array}{l}\text { First Stage F-statistic } \\
\text { P-value for first stage F-statistic }\end{array}$ & & & $\begin{array}{l}4,176 \\
0.000\end{array}$ & & & $\begin{array}{l}3,761 \\
0.000\end{array}$ \\
\hline R-squared & 0.059 & 0.059 & 0.059 & 0.081 & 0.082 & 0.081 \\
\hline
\end{tabular}

The table reports coefficients and standard errors (in brackets) from linear probability models estimated using ordinary least squares (OLS) and two staged least squares (TSLS). Other than those indicated in the table, control variables include year effects, age effect, state effects, state effects interacted with age group, and (log of) family size, whether mother and father present, race (white, black), mother's age, father's age, mother's education (less than 12 or 12 years), father's education (less than 12 or 12 years), and whether the mother or father is unemployed. The sample size is 474,164 for less than excellent health and 376,889 for no doctor visit in the past year. * significant at $10 \%,{ }^{* *}$ significant at $5 \%, * * *$ significant at $1 \%$. 


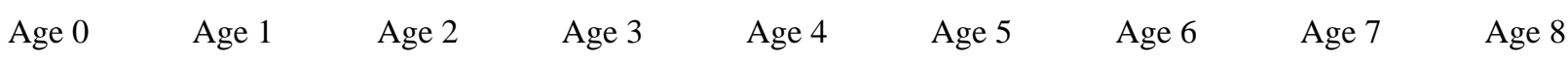

\section{Dependent Variable: Less Than Excellent Health}

Lagged Simulated Eligible

Log Family Income (\$1986)

Log Family Income (\$1986) * 1996-2005

\section{R Squared}

\section{Dependent Variable: No Doctor Visit in the Past Year}

Lagged Simulated Eligible

Log Family Income (\$1986)

Log Family Income (\$1986) * 1996-2005

R Squared

$-0.074$

$[0.019]^{* * *}$

$-0.031$

$[0.002]^{* * *}$

0.008

$[0.003]^{* *}$
$-0.067$

$-0.031$

$[0.002]^{* * *}$

0.008

$[0.003]^{* *}$

$[0.024]^{* * *}$

$-0.064$

$-0.053$

$-0.055$

$-0.031$

$[0.022]^{* * *}$

[0.021]**

$[0.002]^{* * *}$

$-0.032$

$-0.032$

0.008

$[0.002]^{* * *}$

$[0.002]^{* * *}$

[0.022]**

$-0.032$

$-0.061$

$-0.039$

$-0.059$

$[0.021]^{* * *}$

[0.019]**

$-0.032$

[0.019]***

$[0.003]^{* * *} \quad[0.003] * * * \quad[0.003] * * *-[0.03]^{* * *}$

$[0.003]^{* *}$

$[0.003]^{* *} \quad[0.003]^{* *}$

0.008

$0.003]^{* * *}$

0.008

$[0.003]^{* * *}$

$[0.003]^{* *}$

$[0.003]^{* *}$

$[0.003]^{* *}$

0.008

0.064

0.064

0.064

0.064

0.064

0.064

0.064

0.064

0.064

The table reports coefficients and standard errors (in brackets) from linear probability models. Other than those indicated in the table, control variables include state, age and year effects, and (log of) family size, whether mother and father present, race (white, black), mother's age, father's age, mother's education (lesss than 12 or 12 years), father's education (less than 12 or 12 years), and whether the mother or father is unemployed. The sample size is 236,974 for less than excellent health and 187,823 for no doctor visit in the past year. * significant at $10 \%,{ }^{* *}$ significant at $5 \%,{ }^{* * *}$ significant at $1 \%$. 